Research Report

\title{
Which psychological factors influence Internet addiction? Evidence through an integrative model
}

\author{
Jonathan Burnay ${ }^{\mathrm{a}, *}$, Joël Billieux ${ }^{\mathrm{b}}$, Sylvie Blairy ${ }^{\mathrm{a}}$, Frank Larøi ${ }^{\mathrm{a}}$ \\ ${ }^{a}$ Department of Psychology: Cognition and Behaviour, University of Liège, Liège 4000, Belgium \\ ${ }^{\mathrm{b}}$ Laboratory for Experimental Psychopathology (LEP), Psychological Science Research Institute, Catholic University of Louvain, Louvain-la-Neuve 1348, Belgium
}

\section{A R T I C L E I N F O}

Article history:

\section{Keywords:}

Passion

Impulsivity

Social provision

Online survey

Multidimensional

\begin{abstract}
A B S T R A C T
Since the appearance of Internet, several preoccupations have appeared as a result, with Internet addiction being one of the most common. The goals of the present study were twofold. First, to examine which psychological factors are relevant to explain Internet addiction, including impulsivity, passion and social provision. Second, to incorporate all these factors into an integrative model. Based on multiple regressions and path analysis, results revealed a positive relation between Internet addiction and specific impulsivity components (lack of perseverance, urgency) and obsessive passion. Moreover, positive relations were observed between obsessive passion and reassurance of worth, opportunity for nurturance, sensation seeking and harmonious passion. In other words, Internet addiction is related to obsessive passion, but is explained by different psychological factors. Accordingly, both Internet addiction and obsessive passion can be viewed as two important and complementary facets of problematic Internet use.
\end{abstract}

(c) 2014 Elsevier Ltd. All rights reserved.

\section{Introduction}

Internet is a technology that has taken up an increasingly large place in our society over time. It is used by more than 2 billion people worldwide (De Argaez, 2012). In light of such a massive use, new issues appear as a result such as the relation between Internet use and isolation, and the issue of Internet addiction (for a review on epidemiological studies, see Kuss, Griffiths, Karila, \& Billieux, 2014). Internet addiction can be described as a disorder in which an individual's inability to control his or her use of Internet causes marked distress and/or functional impairment (Shapira, Goldsmith, Keck, Khosla, \& McElroy, 1999) and that furthermore creates psychological, social, school and/or work difficulties (isolation, lower grades, conflicts with relatives) (Beard \& Wolf, 2001; Gentile et al., 2011). The main tendency that has attempted to explain Internet addiction consists of viewing this disorder as a "behavioral addiction" marked by high impulsivity and that shares most features with drug addictions (e.g., tolerance, withdrawal, craving, loss of control, relapse) (Beard \& Wolf, 2001; Block, 2008; Shapira et al., 2003). Other approaches include considering Internet addiction in relation to passion theory (Vallerand et al., 2003), or conceptualizing it as a maladaptive coping strategy to

* Corresponding author at: Department of Psychology: Cognition and Behaviour, Boulevard du Rectorat B33, Sart-Tilman, University of Liège, Liège 4000, Belgium. Tel.: +32 43663674; fax: +32 3662808 .

E-mail address: jonathan.burnay@ulg.ac.be (J. Burnay). deal with negative life events or psychopathology (KardefeltWinther, 2014).

The first tendency is based on criticisms of Young's (1996) definition of Internet addiction, where criteria for pathological gambling (which were themselves based on substance abuse criteria) are used to define dysfunctional Internet use as an addictive disorder in which lack of impulse control is a key feature. Specifically, Beard and Wolf (2001) maintain that Young's criteria for Internet addiction are too rigid, subjective and transparent for self-reported measures. They also explain that if Internet addiction is based on pathological gambling criteria, it should be considered as an impulsivity disorder. In this context, Shapira et al. (2003) proposed to classify Internet addiction as an impulse-control disorder, but this classification has also been criticized for being too restrictive. Authors such as Billieux, Gay, Rochat, and Van der Linden (2010), Billieux et al. (2013) and Mottram and Fleming (2009) argue that impulsivity traits do indeed influence Internet addiction, but that other factors also intervene such as personality traits (e.g., extraversion, neuroticism), motives to use Internet (e.g., socialization, escapism, achievement), comorbid psychopathology, using Internet for professional purposes and the primary activity on Internet (gaming, browsing, communicating, downloading and working). Regarding impulsivity, studies have shown that both lack of perseverance (i.e., the tendency to have difficulties remaining focused on demanding and/or boring tasks) and urgency (i.e., the tendency to act rashly when faced with intentional emotional 
states) are related to Internet addiction (Billieux, Gay, Rochat, \& Van der Linden, 2010; Mottram \& Fleming, 2009). More precisely, Mottram and Fleming (2009) evaluated the following in their sample of 272 university students (average age: 24 years): Impulsivity (using the UPPS Impulsive Behavior Scale; Whiteside \& Lynam, 2001), Internet addiction (using the Internet Addiction Test; Young, 1998) and extraversion. Results revealed that lack of perseveration was the only facet of impulsivity positively related to Internet addiction in addition to extraversion and being a nonprofessional user. On a sample of 95 young adults, Billieux et al. (2010) carried out a study on the effects of urgency on three problematic behaviors: Internet dysfunctional use (using the Internet Addiction Test), problematic use of cell-phones and compulsive buying. Results revealed that both urgency and lack of perseverance positively and significantly correlated with Internet addiction symptoms. On the whole, existing studies support that Internet-related disorders are associated with specific facets of the multi-dimensional impulsivity construct, and that other psychological factors are also involved in its etiology (for a review, see Billieux \& Van der Linden, 2012).

Based on the theory of Vallerand et al. (2003), Internet addiction may be seen as the consequence of an obsessive passion (Lafrenière, Vallerand, Donahue, \& Lavigne, 2009; Przybylski, Weinstein, Ryan, \& Rigby, 2009). Passion is defined as a strong inclination towards an activity that people like, that they find important, and in which they invest both time and energy. Further, two kinds of passion may be delineated: harmonious passion versus obsessive passion. Harmonious passion results from an autonomous internalization of the activity into the person's identity that occurs when individuals have freely accepted the activity as important for them without any contingencies attached to it. This type of internalization produces a motivational force to engage willingly in the activity and engenders a sense of volition and personal endorsement about pursuing the activity. The activity moreover occupies a significant place in the person's life, is in harmony with other aspects of his/her life and they feel free to engage in the activity. On the other hand, obsessive passion is the result of a controlled internalization of the activity into one's identity. Such internalization originates from intrapersonal and/ or interpersonal pressure either because certain contingencies are attached to the activity (such as feelings of social acceptance or self-esteem) or because the sense of excitement derived from activity engagement becomes uncontrollable. The activity is perceived as being out of control, and they feel compelled to engage in it because of these internal contingencies. In addition, the activity takes up a disproportionate amount of space in the person's identity and causes conflicts with other activities in the person's life. This theory has been mostly tested in the context of video game use, and has not yet been specifically examined in relation to Internet use. Using the passion scale (Vallerand et al., 2003) and based on a sample of 1324 participants (average age: 24 years), Przybylski et al. (2009) reported that having an obsessive passion for video games increases the time spent playing video games. Likewise, using the passion scale and a questionnaire specially designed for the study, Lafrenière et al. (2009) found, in their sample of participants with an average age of 23 years, that obsessive passion was positively related to both time spent playing and problematic behaviors generally associated with excessive gaming (i.e., irritability, agitation, playing as a coping strategy, incapacity to reduce time spent playing). Thus, passion theory makes an important distinction between an adaptive passionate activity (harmonious passion) and a problematic passionate activity (obsessive passion), which, furthermore, has similar consequences of excessive gaming (Lafrenière et al., 2009).

Moreover, changes in social provision are often considered to be a consequence of Internet addiction. Although not referring specifically to Internet addiction, Weiss (1974) defines social provision as a function that may be obtained from relationships with others and that are needed for individuals to feel adequately supported and to avoid loneliness. Social provision consists of six functions: guidance (advice or information), reliable alliance (assurance that others can be counted upon for tangible assistance), reassurance of worth (recognition of one's competence, skills, and value by others), opportunity for nurturance (sense that others rely upon one for their well-being), attachment (emotional closeness from which one derives a sense of security) and social integration (sense of belonging to a group that shares similar interests, concerns, and recreational activities). A number of studies have examined whether or not Internet use tends to increase or limit social provision, but the results are somewhat contradictory. It seems that studies using a measure that assesses time spend on Internet do not show any effect, or show a positive effect, of Internet use on social provision, supporting the view that high engagement (i.e., the actual number of hours devoted to online activity) has to be distinguished from dysfunctional use (Charlton \& Danforth, 2007). For instance, Hampton, Sessions, Her, and Rainie (2009) have shown that Internet users have more confidants outside the couple, more contact from different cultural backgrounds and have more face-to-face contacts, compared to those who do not use Internet. Subrahmanyam and Lin (2007) did not find a significant relation between time spent on Internet per day and loneliness or parental social provision in their sample of adolescents (average age: 16 years). Wangberg et al. (2007), based on their large sample of participants ranging from 15 to 80 years of age, showed that the more time users spent on Internet per day, the greater their perceived social provision. On the contrary, authors using a psychopathological measure of Internet use seem to find a negative effect of Internet use on social provision. Based on a sample of university students (average age: 21 years), Engelberg and Sjöberg (2004), using the Internet Addiction Test and the UCLA Loneliness Scale (Russell, 1996), showed that Internet addiction is related to loneliness. Similarly, using the Social Avoidance and Distress scale (Watson \& Friend, 1969) and their questionnaire about preference for online interaction, Caplan (2007) observed, in his sample of university students (average age: 19 years) that having social anxiety increased preference for interaction on Internet instead of face-to-face interaction. These findings could support the view that Internet involvement can be viewed as an avoidance behavior since virtual contacts could be perceived as being less stressful for those with high levels of social anxiety. On the other hand, results from Caplan (2007) revealed that a preference for interaction on Internet is positively related to problematic Internet use. Thus, social provision among Internet users is a well-known concern, but it appears that the chosen measure greatly influences the results.

Accordingly, the objective of the current study was to examine which psychological factors are relevant to explain Internet addiction including impulsivity, passion and social provision. Another objective was to investigate, for the first time, the relationship between both kinds of passion and Internet addiction. A final aim was to assimilate all these variables into an integrated model. To the best of our knowledge, no previous studies have taken all these variables simultaneously into account in the context of Internet addiction.

It was hypothesized that Internet addiction is influenced by obsessive passion, impulsivity and social provision. Second, it was hypothesized that obsessive passion is influenced by impulsivity and social provision. More precisely, we postulated that both urgency and lack of perseverance would be significantly related to Internet addiction and obsessive passion. Finally, regarding social provision, it was hypothesized that this would be negatively related to obsessive passion and positively related to harmonious passion. 


\section{Material and methods}

\subsection{Participants and procedure}

The study consists of an online survey that was realized on a convenience sample of participants recruited on Internet via announces, e-mails and social networks. Further, people were asked to share the survey with others in order to create a "snowball effect". In order to generalize our results to the general population as best as possible, we applied this study to a sample with large variability in terms of age and profession. A total of 644 subjects were recruited. However, 142 participants were excluded from the study (131 did not complete the entire survey and 11 did not answer some of the items), leaving a total of 502 participants. The study was approved by the local ethics committee. All participants gave online consent prior to starting the online survey. Anonymity of the participants was guaranteed (no personal data on the participants were collected, including their Internet Protocol [IP] address). Minors were also able to participate on the condition that they orally asked their parents for parental permission. Participants' characteristics are presented in Table 1.

\subsection{Material}

Participants were asked to provide information regarding their age, gender, profession and time spend on Internet (per week). They were also asked to state their principal activity on Internet by choosing one category among the following: online gaming, gambling, pornography, communication (e-mail, chat and forums), online buying, programming and research.

A number of questionnaires were also administered. A French version (Khazaal et al., 2008) of the Internet Addiction Test (IAT;
Young, 1998) was administered. Participants also completed a French version (Van der Linden et al., 2006) of the UPPS Impulsive Behavior Scale (UPPS; Whiteside \& Lynam, 2001). The UPPS measures four facets of impulsivity: negative urgency (e.g., "When I feel bad, I will often do things I later regret in order to make myself feel better now"), lack of perseverance (e.g., "I concentrate easily"), lack of premeditation (e.g., "I am a cautious person") and sensation seeking (e.g., "I will try anything once"). The Passion Scale (Vallerand et al., 2003) evaluates the level of harmonious and obsessive passion. A French version (Caron, 1996) of the Social Provisions Scale (SPS; Cutrona \& Russel, 1987) was administered, which evaluates the presence and level of the six functions of social support (guidance, reliable alliance, reassurance of worth, opportunity for nurturance, attachment and social integration). Participants completed the French version (Bourque \& Beaudette, 1982) of the Beck Depression Inventory 2nd edition (BDI-II; Beck, Steer, \& Brown, 1996). Finally, a French version (Spielberger, BruchonSchweitzer, \& Paulhan, 1993) of the Trait Anxiety Inventory (STAI-T; Spielberger, Gorssuch, Lushene, Vagg, \& Jacobs, 1983) was administered.

\subsection{Statistical analyses}

First, descriptive results were conducted. Then, multiple regression analyses were used in order to reduce the number of variables to be included in the model. The objective of these analyses is to ensure an overidentified and parsimonious path analysis (Diamantopoulos \& Siguaw, 2008). An overidentified model is a model where the number of parameters to be estimated is inferior to the number of variances and covariances among the manifest variables. Finally, all these results were integrated into an exploratory path analysis using LISREL software.

Table 1

Demographic characteristics of the sample.

\begin{tabular}{|c|c|c|c|c|}
\hline Sample size $(N)$ & Age (SD; Minimum-Maximum) & $\operatorname{Sex}(M / F)$ & Profession $(N)$ & Principal activity $(N)$ \\
\hline 502 & 28.19 years $(12.52 ; 14-75)$ & $146 / 356$ & $\begin{array}{l}\text { Student }=56.6 \%(284) \\
\text { Health field }=9.8 \%(49) \\
\text { Civil servant }=5.9 \%(30) \\
\text { Unemployed }=4.3 \%(22) \\
\text { Retired }=3.8 \%(19) \\
\text { Teaching }=3.8 \%(19) \\
\text { Military }=2.2 \%(11) \\
\text { Independent }=1.2 \%(6) \\
\text { Engineer }=1 \%(5) \\
\text { Informatics }=1 \%(5) \\
\text { Law field }=1 \%(5) \\
\text { Other }=9.4 \%(47)\end{array}$ & $\begin{array}{l}\text { Communication }=57.3 \%(288) \\
\text { Research }=28.9 \%(145) \\
\text { Gaming }=11.6 \%(58) \\
\text { Online buying }=1.2 \%(6) \\
\text { Programing }=1 \%(5)\end{array}$ \\
\hline
\end{tabular}

Table 2

Descriptive results and reliability.

\begin{tabular}{|c|c|c|c|c|}
\hline & Mean & SD & Range & Reliability coefficient $(\alpha)$ \\
\hline Time spent on Internet & 22.21 & 15.86 & $1-100$ & 1 \\
\hline Internet Addiction Test & 33.13 & 12.36 & $2-90$ & .93 \\
\hline Urgency & 28.32 & 7.09 & $12-48$ & .83 \\
\hline Lack of perseverance & 21.14 & 4.43 & $12-33$ & .81 \\
\hline Lack of premeditation & 19.67 & 5.59 & $10-40$ & .83 \\
\hline Sensation seeking & 29.66 & 8.07 & $12-47$ & .77 \\
\hline Harmonious passion & 24.54 & 6.82 & $6-42$ & .79 \\
\hline Obsessive passion & 11.33 & 5.61 & $6-35$ & .89 \\
\hline Guidance & 13.74 & 2.27 & $5-16$ & .76 \\
\hline Reliable alliance & 14.10 & 2.09 & $5-16$ & .65 \\
\hline Reassurance of worth & 11.44 & 1.66 & $4-16$ & .66 \\
\hline Opportunity for nurturance & 11.46 & 1.45 & $4-16$ & .66 \\
\hline Attachment & 13.32 & 2.03 & $4-16$ & .74 \\
\hline Social integration & 13.06 & 2.05 & $4-16$ & .67 \\
\hline BDI & 9.03 & 7.53 & $0-44$ & .90 \\
\hline STAI-T & 49.23 & 4.94 & $36-65$ & .90 \\
\hline
\end{tabular}




\section{Results}

\subsection{Descriptive results}

See Table 2.

\subsection{Regression analysis}

Four multiple regression analyses were performed to find out which variables explained Internet addiction, obsessive passion, harmonious passion and hours per week (see Table 3). None of

Table 3

Regression analysis.

\begin{tabular}{|c|c|c|c|c|c|c|c|}
\hline Dependent variable & Independent variable & $B$ & SE B & $T$ & $p$ & $\beta$ & $R^{2}$ \\
\hline \multirow[t]{16}{*}{ Internet Addiction Test } & Age & -0.14 & 0.03 & -3.60 & $<.001$ & -.14 & .411 \\
\hline & Hours per week & 0.15 & 0.03 & 5.06 & $<.001$ & .19 & \\
\hline & Harmonious passion & 0.10 & 0.06 & 1.49 & .136 & .05 & \\
\hline & Obsessive passion & 0.77 & 0.08 & 8.92 & $<.001$ & .35 & \\
\hline & Urgency & 0.17 & 0.07 & 2.20 & $<.01$ & .09 & \\
\hline & Lack of premeditation & -0.05 & 0.10 & -0.56 & .571 & -.02 & \\
\hline & Lack of perseverance & 0.41 & 0.11 & 3.45 & $<.01$ & .14 & \\
\hline & Sensation seeking & -0.01 & 0.05 & -0.20 & .838 & -.01 & \\
\hline & STAI Trait & 0.10 & 0.09 & 1.06 & .289 & .04 & \\
\hline & Depression & 0.19 & 0.07 & 2.52 & $<.05$ & .12 & \\
\hline & Attachment & -0.27 & 0.35 & -0.77 & .441 & -.04 & \\
\hline & Reliable alliance & -0.33 & 0.32 & -1.00 & .313 & -.05 & \\
\hline & Guidance & -0.06 & 0.31 & -0.19 & .843 & -.01 & \\
\hline & Social integration & 0.27 & 0.27 & 0.98 & .324 & .04 & \\
\hline & Reassurance of worth & 0.82 & 0.33 & 2.50 & $<.05$ & .11 & \\
\hline & Opportunity for nurturance & 0.56 & 0.33 & 1.70 & .089 & .06 & \\
\hline \multirow[t]{16}{*}{ Obsessive passion } & Age & 0.05 & 0.01 & 2.97 & $<.01$ & .12 & .324 \\
\hline & Hours per week & 0.03 & 0.01 & 2.31 & $<.05$ & .09 & \\
\hline & Harmonious passion & 0.12 & 0.03 & 3.88 & $<.001$ & .15 & \\
\hline & Urgency & 0.08 & 0.03 & 2.22 & $<.05$ & .10 & \\
\hline & Lack of premeditation & 0.01 & 0.04 & 0.21 & .833 & .01 & \\
\hline & Lack of perseverance & -0.05 & 0.05 & -0.93 & .350 & -.04 & \\
\hline & Sensation seeking & -0.01 & 0.02 & -0.35 & .725 & -.01 & \\
\hline & STAI Trait & 0.03 & 0.04 & 0.63 & .523 & .02 & \\
\hline & Depression & 0.08 & 0.03 & 2.33 & $<.05$ & .12 & \\
\hline & Attachment & -0.02 & 0.17 & -0.13 & .894 & -.01 & \\
\hline & Reliable alliance & 0.03 & 0.16 & 0.24 & .808 & .01 & \\
\hline & Guidance & -0.11 & 0.15 & -0.74 & .455 & -.04 & \\
\hline & Social integration & -0.04 & 0.13 & -0.35 & .726 & -.01 & \\
\hline & Reassurance of worth & 0.16 & 0.16 & 1.00 & .313 & .04 & \\
\hline & Opportunity for nurturance & -0.16 & 0.16 & -1.00 & .317 & -.04 & \\
\hline & Internet Addiction Test & 0.18 & 0.02 & 8.92 & $<.001$ & .40 & \\
\hline \multirow[t]{16}{*}{ Harmonious passion } & Age & 0.01 & 0.02 & 0.10 & .918 & .01 & .169 \\
\hline & Hours per week & 0.04 & 0.02 & 2.47 & $<.01$ & .11 & \\
\hline & Urgency & -0.04 & 0.05 & -0.86 & .386 & -.04 & \\
\hline & Lack of premeditation & -0.04 & 0.06 & -0.73 & .462 & -.03 & \\
\hline & Lack of perseverance & -0.13 & 0.07 & -1.65 & .098 & -.08 & \\
\hline & Sensation seeking & 0.12 & 0.03 & 3.22 & $<.001$ & .14 & \\
\hline & STAI Trait & 0.10 & 0.06 & 1.61 & .106 & .07 & \\
\hline & Depression & -0.11 & 0.05 & -2.29 & $<.05$ & -.13 & \\
\hline & Attachment & -0.09 & 0.23 & -0.39 & .690 & -.02 & \\
\hline & Reliable alliance & -0.09 & 0.21 & -0.43 & .661 & -.02 & \\
\hline & Guidance & 0.11 & 0.20 & 0.58 & .562 & .03 & \\
\hline & Social integration & 0.21 & 0.18 & 1.15 & .248 & .06 & \\
\hline & Reassurance of worth & 0.39 & 0.21 & 1.80 & .071 & .09 & \\
\hline & Opportunity for nurturance & 0.45 & 0.21 & 2.11 & .035 & .09 & \\
\hline & Internet Addiction Test & 0.04 & 0.02 & 1.49 & .136 & .08 & \\
\hline & Obsessive passion & 0.23 & 0.06 & 3.88 & $<.001$ & .19 & \\
\hline \multirow[t]{16}{*}{ Hour per week } & Age & -0.14 & 0.05 & -2.51 & $<.05$ & -.11 & .222 \\
\hline & Hour per week & -0.15 & 0.11 & -1.36 & .171 & -.07 & \\
\hline & Urgency & -0.09 & 0.14 & -0.66 & .504 & -.03 & \\
\hline & Lack of premeditation & 0.40 & 0.17 & 2.27 & $<.05$ & .11 & \\
\hline & Lack of perseverance & 0.16 & 0.08 & 1.92 & .054 & .08 & \\
\hline & Sensation seeking & -0.07 & 0.14 & -0.51 & .607 & -.02 & \\
\hline & STAI Trait & 0.11 & 0.11 & 0.94 & .346 & .05 & \\
\hline & Depression & -0.74 & 0.52 & -1.42 & .153 & -.09 & \\
\hline & Attachment & -0.10 & 0.48 & -0.21 & .829 & -.01 & \\
\hline & Reliable alliance & 0.11 & 0.46 & 0.24 & .807 & .01 & \\
\hline & Guidance & 0.75 & 0.41 & 1.83 & .066 & .09 & \\
\hline & Social integration & 0.22 & 0.49 & 0.46 & .640 & .02 & \\
\hline & Reassurance of worth & -0.13 & 0.48 & -0.26 & .789 & -.01 & \\
\hline & Internet Addiction Test & 0.33 & 0.06 & 5.06 & $<.001$ & .25 & \\
\hline & Obsessive passion & 0.31 & 0.13 & 2.31 & $<.05$ & .11 & \\
\hline & Harmonious passion & 0.25 & 0.10 & 2.47 & $<.05$ & .10 & \\
\hline
\end{tabular}


the variables included in the various regression analyses were found to be collinear. A first multiple regression analysis was used in order to examine which psychological factors (impulsivity, passion, social provision) predict scores on the IAT, while controlling for age, depression, anxiety and time spent on Internet. Two other multiple regression analyses were carried out in order to examine which psychological factors (impulsivity facets, social provision) predict passion, while controlling for the other kind of passion, Internet addiction, age, depression, anxiety and time spent on Internet. A last multiple regression analysis was used to explore which variables among social provision, impulsivity, Internet addiction, passion, depression, anxiety and age, predict the time spent on Internet.

\subsection{Path analysis}

All results were thereafter integrated into a general model of exploratory regression by using LISREL. Relations between variables were established using the results of the multiple regressions and the LISREL suggestions of modification (the software suggests modifications of the paths and covariance error in order to obtain a better fit). The following variables were entered into the path analysis (Fig. 1): age, time spent on Internet, Internet addiction, obsessive passion, harmonious passion, urgency, lack of perseverance, sensation seeking, depression, reassurance of worth, and opportunity for nurturance. The following causality relations were calculated: (1) Internet addiction is explained by urgency, lack of perseverance, obsessive passion, reassurance of worth, depression and age; (2) obsessive passion is explained by Internet addiction, urgency, sensation seeking, harmonious passion, reassurance of worth, opportunity for nurturance, depression and age; (3) harmonious passion is explained by Internet addiction, sensation seeking, opportunity for nurturance and depression; and (4) time spent on Internet is explained by Internet addiction, harmonious passion, obsessive passion, lack of perseverance and age.
This model reveals a correct adequacy $\left(\chi^{2}(11)=21.402, p<.05\right.$, RMSEA $=.043, \quad G F I=.992, \quad A G F I=.954, \quad N F I=.979, \quad N N F I=.945$, $C F I=.989$ ). It shows that (1) Internet addiction is explained (in order of importance) by obsessive passion, depression, lack of perseverance and urgency, but not by reassurance of worth $\left(R^{2}=.366\right)$; (2) obsessive passion (in order of importance) is explained by harmonious passion, reassurance of worth, sensation seeking and opportunity for nurturance, but not by age, urgency and depression $\left(R^{2}=.174\right)$; (3) harmonious passion is explained (in order of importance) by Internet addiction and depression, but not by opportunity for nurturance and sensation seeking $\left(R^{2}=.208\right)$; and (4) time spent on Internet is explained (in order of importance) by Internet addiction, obsessive passion, age, harmonious passion and lack of perseverance $\left(R^{2}=.205\right)$.

\section{Discussion}

This is the first time that impulsivity, passion and social provision are all included in the same study in order to examine a multidimensional model of Internet addiction. Further, and to the best of our knowledge, no other studies have examined the relation between both kinds of passion and Internet addiction.

The results confirmed that Internet addiction is a multidimensional phenomenon influenced by impulsivity and passion. In particular, the model validated in the present study identified urgency, lack of perseverance, obsessive passion, depression, and age - all as predictors of Internet addiction. Furthermore, this model explained $36.6 \%$ of Internet addiction symptoms variance. Thus, our findings support the view that multiple and heterogeneous factors are involved in Internet addiction. At the same time, however, this means that a further $63.4 \%$ of Internet addiction variance remains to be identified and therefore future studies are needed to identify these factors. For example, the specific motives that drive the involvement in online activities (e.g., immersion, escapism, achievement, social affiliation) should be considered

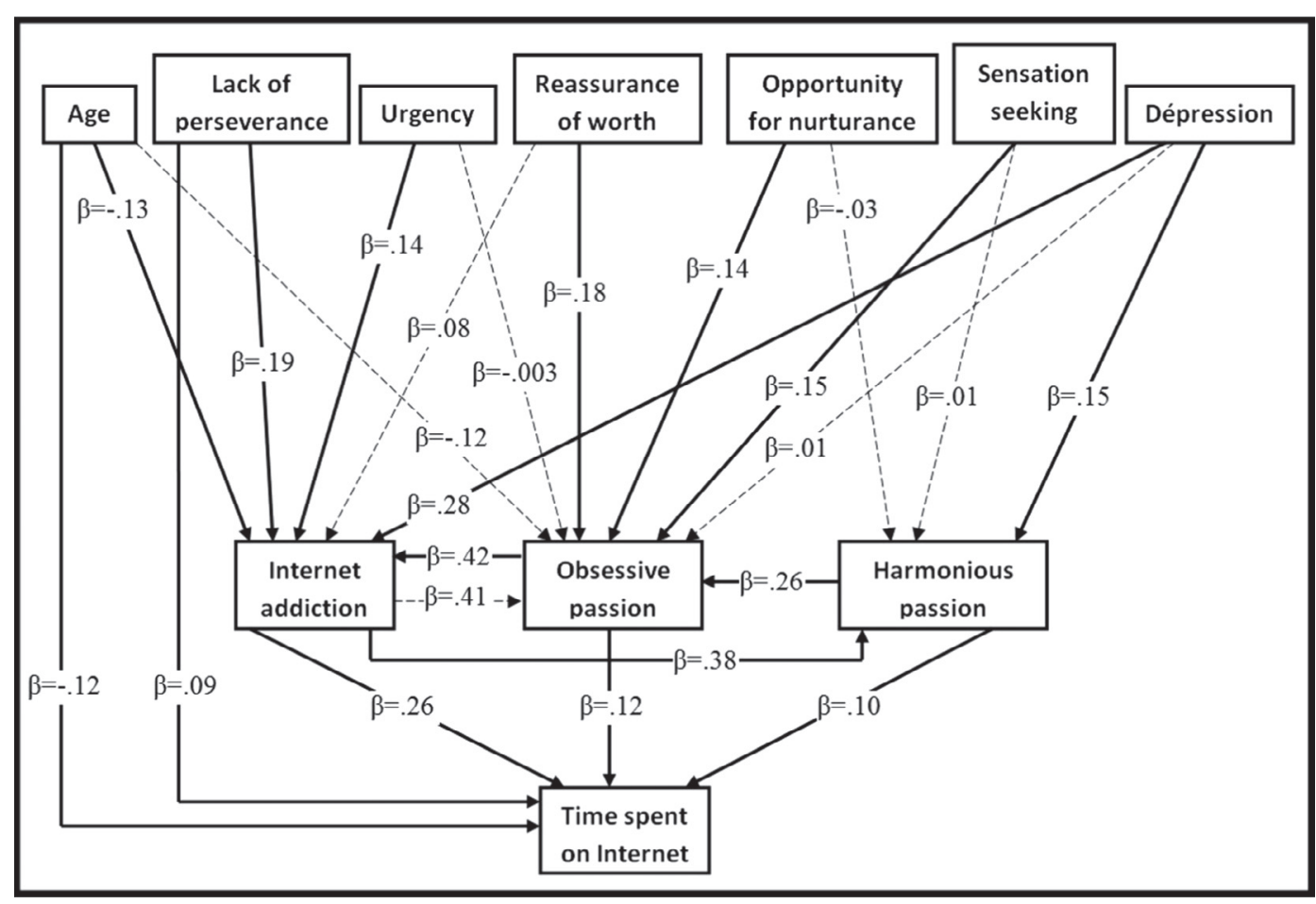

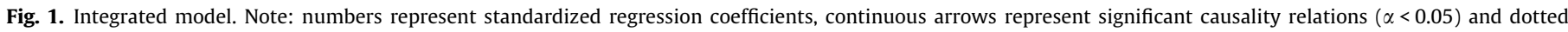
arrows represent nonsignificant causality relations $(\alpha>0.05)$. 
(e.g., Billieux et al., 2013; Kardefelt-Winther, 2014). The multidimensional model validated in the present study also suggested those factors that influence obsessive passion, namely, sensation seeking, opportunity for nurturance, reassurance of worth and harmonious passion. However, as this is the first study to include passion in a model of Internet addiction, our findings need to be replicated in future studies. Further, since our sample comprised more women than men, and also mostly consisted of students the model needs to be confirmed in samples which address these limits in order to allow proper generalization of the findings.

More precisely, and as expected, Internet addiction was found to be significantly related to urgency, lack of perseverance and obsessive passion, but not to the six factors related to social provision. First, Internet addiction was positively related to urgency, conceptualized as the tendency to act rashly when faced with negative affect. Thus, in situations of negative affect, individuals can experience an urge to use Internet and a loss of control on this activity. These results suggest that Internet use, for certain individuals, could be a way to relieve negative affect, and as such can be conceptualized as a maladaptive coping strategy to deal with negative life events, emotions or thoughts (Billieux et al., 2011, 2013; Kardefelt-Winther, 2014). This finding is in accordance with the results of other studies pointing to urgency as a risk factor for the involvement in problematic behaviors that serve to alleviate negative affect on the short term, despite their long term negative outcomes (Anestis, Selby, \& Joiner, 2007; Billieux et al., 2010). Second, Internet addiction was related to lack of perseverance, an impulsivity facet that is defined as an inability to remain focused on demanding tasks, and related to a greater proneness to experience intrusive or non-relevant thoughts (Gay, d'Acremont, Rochat, Billieux, \& Van der Linden, 2008; Gay et al., 2010). A possible explanation regarding the link between Internet addiction and lack of perseverance is that a proneness to experience mind wandering, attention fluctuation or intrusive/irrelevant thoughts can promote the involvement in Internet-related activities (e.g., someone overwhelmed by thoughts regarding the next time he/she will go online). It has indeed been shown that intrusive thoughts can trigger craving episodes (the stronger desire to perform a behavior or consume a substance) and translate into compulsions (May, Andrade, Panabokke, \& Kavanagh, 2004). Another tentative explanation for the relation between Internet addiction and lack of perseverance is that Internet use could be a way to control or reduce irrelevant or intrusive thoughts.

Internet addiction was also found to be related to both obsessive and harmonious passion. This finding is partly in accordance with Lafrenière et al. (2009) and Przybylski et al. (2009) who have also found that Internet addiction is the consequence of an obsessive passion. In addition, the findings from the present study reveal that Internet addiction may be related to a more adaptive form of passion as well, that is, harmonious passion. This suggests that Internet use may be used in an adaptive way for some individuals and in a more maladaptive manner for others. These results could be explained by the positive correlation between harmonious passion and obsessive passion, which is consistent with Przybylski et al. (2009). This indicates that passionate activity could be partly an obsessive passion and partly a harmonious passion. The shared variance of these two constructs probably also account for the positive relation between harmonious passion and depression. It is worth noting that this study provides little information about the factors influencing harmonious passion and thus future studies are required in order to clarify the uniqueness of these two types of passion, and their specific relations to problematic behaviors.

Internet addiction and obsessive passion could be seen as distinct facets of problematic Internet use because of the different factors that influence them. Internet addiction is positively related to urgency and lack of perseverance, while obsessive passion is related to sensation seeking and social provision. This means that Internet addiction is more influenced by internal factors, such as loss of control in emotional contexts and difficulty to inhibit irrelevant thoughts, than by external factors such as interpersonal factors. On the other hand, obsessive passion seems to be more influenced by externally-oriented factors such as pursuing activities that are exciting and interpersonal factors. In order to elucidate more clearly the difference between these two facets (obsessive passion and Internet addiction), it may be helpful to consider specific items from these measures. In this context, it appears that the Internet Addiction Test evaluates the negative consequences of Internet use (e.g., "How often do others in your life complain to you about the amount of time you spend on-line?" or "How often do you lose sleep due to late-night log-ins?"). On the other hand, the passion scale seems to assess whether or not the person has a problematic interest for the activity (e.g., "This activity is the only thing that really turns me on" or "I have almost an obsessive feeling for this activity"). It seems therefore relevant to use both the Internet Addiction Test and Passion Scale as complementary measures. Further, the results of this study show that Internet use could be divided into several factors such as problematic behavior and problematic interest. However, other facets could also be relevant and therefore should be considered in other studies, such as antisocial behavior on Internet (e.g., verbal aggression, cyberbullying, hacking, fraud, etc.).

Our second hypothesis concerning a positive relation between obsessive passion and impulsivity, and a negative relation with social provision - was partially verified. In particular, obsessive passion was positively influenced by harmonious passion, two factors of social provision (reassurance of worth and opportunity for nurturance) and sensation seeking. The relation with sensation seeking could be explained in that certain individuals may satisfy sensations while using Internet, especially those who primarily use Internet for gaming, social network or pornography. However, at the same time, one could also argue that all types of Internet activity elicit a certain degree of sensation as it allows people to do a lot a different activities (such as chatting, and watching a movie), within a short period of time, which probably represents an immediate positive reinforcement. A better moderator of the relation between obsessive passion and sensation seeking could be the time spent on Internet, and indeed there was a significant positive relation between time spent on Internet and sensation seeking $(r=.16 ; p<.001)$. Nevertheless, a more direct examination of the relations between sensation seeking and Internet use merits further investigation. The relation between obsessive passion, and reassurance of worth and opportunity for nurturance, is, however, more difficult to account for. It was hypothesized that an obsessive passion does not necessarily lead to social difficulties as previously supposed. Considering that the large majority of our participants use Internet for communication activities, one explanation could be that Internet users with an obsessive passion experience social satisfaction from online interaction. Another assumption could be that the two functions of social provision (reassurance of worth and opportunity for nurturance) that correlated with obsessive passion are functions that bring responsibilities that could be stressful. For instance, obsessive passion is related to reassurance of worth, which is the recognition by others of our competences, skills and values (Cutrona \& Russel, 1987). One could suppose that this function is related to more employment responsibilities. Also, Cutrona and Russel (1987) suggest that people with a high opportunity for nurturance often have a spouse and/or children to care about. It could be assumed that people with higher responsibilities use Internet as a coping strategy. Future studies are, however, needed in order to verify the existence of a mediator effect of responsibilities between obsessive passion and social provision. 
The findings of the present study have clinical implications. Indeed, and based on the findings showing that Internet addiction is influenced by impulsivity, obsessive passion and depression - an action on these factors could involve helping individuals deal with Internet addiction. For instance, depression and impulsivity could be targeted with specific psychological interventions (e.g., improvement of emotion regulation, by using mindfulness-based therapy, and the optimization of self-control). By acting on impulsivity and depression, the obsessive passion would disappear in profit of a harmonious passion.

\section{Conclusion}

In sum, the results of the present study help contribute to a better understanding of the psychological factors involved in Internet addiction. Both impulsivity and passion were found to be particularly important to explain Internet addiction, but this was not the case for social provision. Moreover, passion seems to be better explained by impulsivity and social provision. Even when controlling for these factors (passion, social provision, depression), impulsivity still influences Internet addiction. As a conclusion, one of the main findings of the current study is that Internet dysfunctional use can arise from obsessive passion and/or a tendency to engage in online behaviors as a coping strategy. This is consistent with the recent view that Internet addiction can be conceptualized either as a primary disorder (mostly driven by an obsessive passion) or a secondary disorder (e.g., a strategy to cope with depression symptoms, social anxiety, etc.).

\section{Acknowledgments}

The authors thank Julien Laloyaux and Aurélie Wagener for having read a draft of the manuscript.

\section{References}

Anestis, M. D., Selby, E. A., \& Joiner, T. E. (2007). The role of urgency in maladaptive behaviors. Behaviour Research and Therapy, 45, 3018-3029.

Beard, K., \& Wolf, E. (2001). Modification in the proposed diagnostic criteria for Internet addiction. Cyberpsychology \&' Behavior, 4, 377-383.

Beck, A., Steer, R., \& Brown, G. (1996). Manual for the beck depression inventory-II. San Antonio, TX: Psychological Corporation.

Billieux, J., Chanal, J., Khazaal, Y., Rochat, L., Gay, P., Zullino, D., et al. (2011). Psychological predictors of problematic involvement in Massively Multiplayer Online Role Playing Games (MMORPG): Illustration in a sample of male cybercafés players. Psychopathology, 44, 165-171.

Billieux, J., Gay, P., Rochat, L., \& Van der Linden, M. (2010). The role of urgency and its underlying psychological mechanisms in problematic behaviours. Behaviour Research and Therapy, 48, 1085-1096.

Billieux, J., \& Van der Linden, M. (2012). Problematic use of the Internet and selfregulation: A review of the initial studies. The Open Addiction Journal, 5(Suppl. 1: M4), 24-29.

Billieux, J., Van der Linden, M., Achab, S., Khazaal, Y., Paraskevopoulos, L., Zullino, D., et al. (2013). Why do you play World of Warcraft? An in-depth exploration of self-reported motivations to play online and in-game behaviours in the virtual world of Azeroth. Computers in Human Behavior, 29, 103-109.

Block, J. J. (2008). Issues for DSM-V: Internet addiction. American Journal of Psychiatry, 165, 306-307.

Bourque, P., \& Beaudette, D. (1982). Psychometric study of the beck depression inventory on a sample of French-speaking university students. Canadian Journal of Behavioural Science, 14, 211-218.

Caplan, S. (2007). Relations among loneliness, social anxiety, and problematic Internet use. Cyberpsychology \&' Behavior, 10, 234-242.

Caron, J. (1996). L'Échelle de provisions sociales: Une validation québécoise. Santé mentale au Québec, 21, 158-180.

Charlton, J. P., \& Danforth, I. D. W. (2007). Distinguishing addiction and high engagement in the context of online game playing. Computers in Human Behavior, 23, 1531-1548.

Cutrona, C. E., \& Russel, D. W. (1987). The provisions of social support and adaptation to stress. Advance in Personal Relationships, 1, 37-67.
De Argaez, E., (2012). Internet World Stats. En ligne: <http:/ www.Internetworldstats.com/> consulté le 09 avril 2012.

Diamantopoulos, A., \& Siguaw, J. (2008). Introducing LISREL. London, England: SAGE Publication.

Engelberg, E., \& Sjöberg, L. (2004). Internet use, social skills, and adjustment. Cyberpsychology E' Behavior, 7, 41-47.

Gay, P., Courvoisier, D. S., Billieux, J., Rochat, L., Schmidt, R. E., \& Van der Linden, M. (2010). Can the distinction between intentional and unintentional interference control help differentiate varieties of impulsivity? Journal of Research in Personality, 44, 46-52.

Gay, P., d'Acremont, M., Rochat, L., Billieux, J., \& Van der Linden, M. (2008) Heterogeneous inhibition processes involved in different facets of self-reported impulsivity: Evidence from a community sample. Acta Psychologica, 129 332-339.

Gentile, D. A., Choo, H., Liau, A., Sim, T., Li, D., Fung, D., et al. (2011). Pathological video game use among youths: A two-year longitudinal study. Pediatrics, 127, 319-329.

Hampton, K. N., Sessions, L. F., \& Her, E. J., Rainie, L. (2009). Social Isolation and New Technology: How the Internet and Mobile Phones Impact Americans' Social Networks, Retrieved from <http://www.pewInternet.org/Reports/2009/18 Social-Isolation-and-New-Technology.aspx>.

Kardefelt-Winther, D. (2014). A conceptual and methodological critique of Internet addiction research: Towards a model of compensatory Internet use. Computers in Human Behavior, 31, 351-354.

Khazaal, Y., Billieux, J., Thorens, G., Khan, R., Louati, Y., Scarlatti, E., et al. (2008) French validation of the Internet addiction test. Cyberpsychology \& Behavior, 11 703-706.

Kuss, D. J., Griffiths, M. D., Karila, L., \& Billieux, J. (2014). Internet addiction: A literature review of epidemiological research for the last decade. Current Pharmaceutical Design, 20, 4026-4052.

Lafrenière, M.-A. K., Vallerand, R. J., Donahue, R., \& Lavigne, G. L. (2009). On the costs and benefits of gaming: The role of passion. Cyberpsychology E Behavior, 12 285-290.

May, J., Andrade, J., Panabokke, N., \& Kavanagh, D. (2004). Images of desire: Cognitive models of craving. Memory, 12, 447-461.

Mottram, A., \& Fleming, M. (2009). Extraversion, impulsivity, and online group membership as predictors of problematic Internet use. Cyberpsychology $\varepsilon$ Behavior, 12, 319-321.

Przybylski, A. K., Weinstein, N., Ryan, R. M., \& Rigby, C. S. (2009). Having to versus wanting to play: Background and consequences of harmonious versus obsessive engagement in video games. Cyberpsychology \& Behavior, 12, 485-492.

Russell, D. (1996). The UCLA loneliness scale (version 3): Reliability, validity, and factor structure. Journal of Personality Assessment, 66, 20-40.

Shapira, N., Goldsmith, T., Keck, P., Khosla, U., \& McElroy, S. (1999). Psychiatric features of individuals with problematic Internet use. Journal of Affective Disorders, 57, 267-272.

Shapira, N., Lessig, M., Goldsmith, T., Szabo, S., Lazoritz, M., Gold, M., et al. (2003). Problematic Internet use: Proposed classification and diagnostic criteria. Depression and Anxiety, 17, 207-216.

Spielberger, C., Bruchon-Schweitzer, M., \& Paulhan, I. (1993). Inventaire d'anxiety état-trait forme $Y(S T A I-Y)$. Paris, France: édition du centre de psychologie appliquée.

Spielberger, C. D., Gorssuch, R. L., Lushene, P. R., Vagg, P. R., \& Jacobs, G. A. (1983) Manual for the state-trait anxiety inventory. Palo Alto, CA: Consulting Psychologists Press.

Subrahmanyam, K., \& Lin, G. (2007). Adolescent on the net: Internet use and wellbeing. Adolescence, 42, 659-677.

Vallerand, R. J., Blanchard, C., Mageau, G., Koestner, R., Ratelle, C., Léonard, M., et al. (2003). Les passions de l'âme: On obsessive and harmonious passion. Journal of Personality and Social Psychology, 85, 756-767.

Van der Linden, M., d'Acremont, M., Zermatten, A., Jermann, F. Larøi, F., Willems, S. et al. (2006). A French adaptation of the UPPS impulsive behavior scale: Confirmatory factor analysis in a sample of undergraduate students. European Journal of Psychological Assessment, 22, 38-42.

Wangberg, S., Andreassen, H., Prokosch, H., Mariavogos Santana, S., Sørensen, T., \& Chronaki, C. (2007). Relations between Internet use, socio-economic status (SES), social support and subjective health. Health Promotion International, 23 70-77.

Watson, D., \& Friend, R. (1969). Measurement of social evaluation anxiety. Journal of Consulting and Clinical Psychology, 33, 448-457.

Weiss, R. S. (1974). The provisions of social relationships. In Z. Rubin (Ed.), Doing unto others (pp. 17-26). Englewood Cliffs, NJ: Prentice-Hall.

Whiteside, S., \& Lynam, D. (2001). The five factor model and impulsivity: Using a structural model of personality to understand impulsivity. Personality and Individual Differences, 30, 669-689.

Young, K. (1996). Internet addiction: The emergence of a new clinical disorder. Paper presented at the 104th annual meeting of the American Psychological Association, Toronto, Canada.

Young, K. (1998). Caught in the net. New York: John Wiley \& Sons. 